\title{
Notas sobre gênero, tecnologia e
}

videogames

\section{Notes on gender, technology and videogames}

Apuntes sobre género, tecnología y videojuegos
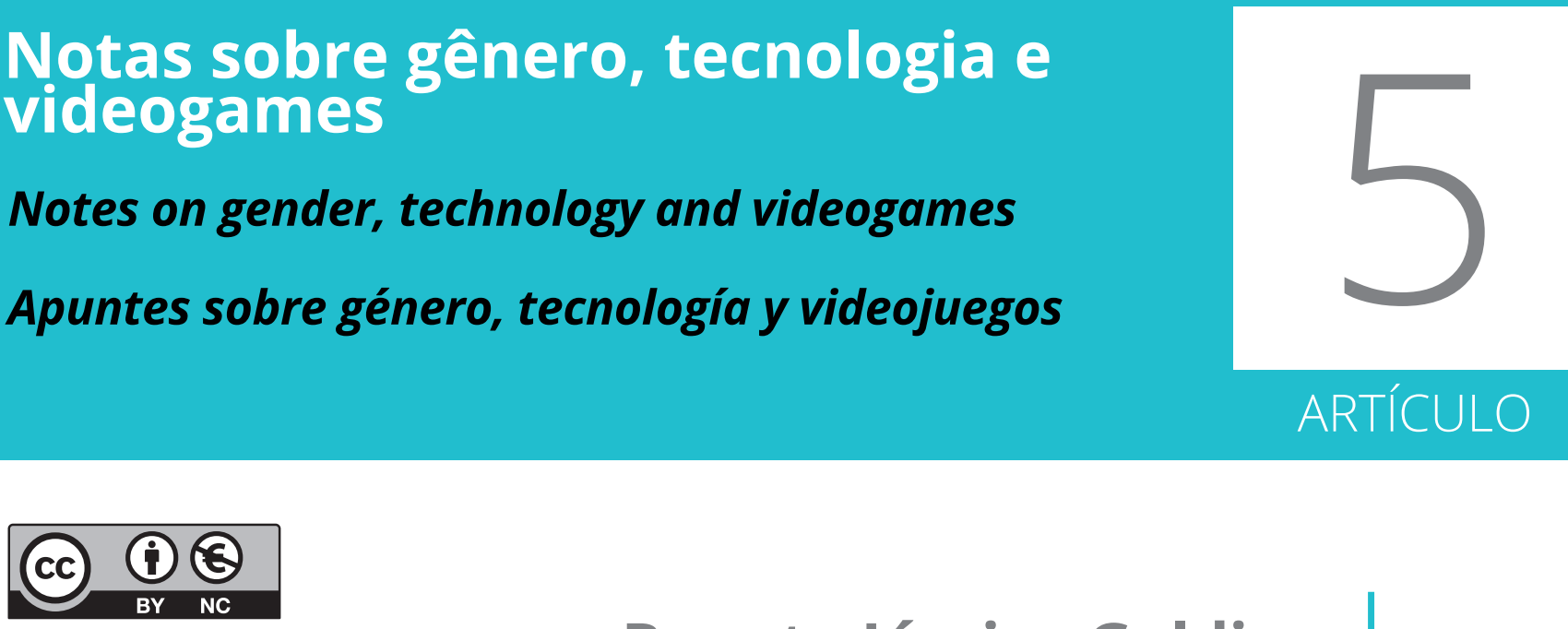

\section{Renata Jéssica Galdino}

Pontifícia Universidade Católica de Campinas (PUC-Campinas)

Mestre em Linguagens, Mídia e Arte pela PUC-Campinas. Bacharel em Publicidade e Propaganda pela Universidade Paulista.

rejgaldino@gmail.com

orcid.org/0000-0003-3111-2737

\section{Tarcisio Torres Silva}

Pontifícia Universidade Católica de Campinas (PUC-Campinas)

Professor pesquisador em regime de dedicação integral da PUC-Campinas. Membro do corpo docente do mestrado em Linguagens, Mídia e Arte na mesma universidade. É doutor em Artes Visuais (2013) e mestre em Artes (2008) pela Universidade Estadual de Campinas. Fez estágio de doutorado no departamento de Estudos Culturais, em Goldsmiths, Universidade de Londres (2011). Possui graduação em Ciências Sociais pela Universidade de São Paulo (2001) e em Comunicação Social com ênfase em Publicidade e Propaganda pela Escola Superior de Propaganda e Marketing (1998).

tartorres@gmail.com

orcid.org/0000-0001-9347-7585

RECEBIDO: 18 de dezembro de 2019 / ACEITO: 27 de janeiro de 2020

\section{Resumo}

Neste trabalho, buscamos investigar as brechas digitais geradas pelas hierarquias de gênero que afetam a maneira como as tecnologias são desenvolvidas, difundidas e apropriadas pelas mulheres. Para tanto, mostramos algumas relações entre gênero e tecnologia a fim de fazermos a aproximação com o universo dos games. Segue então um resgate da concepção dos games como "coisa de menino", de forma a mostrar como essa tecnologia foi aos poucos sendo distanciada do mundo das meninas. Hoje, o caminho inverso vem sendo feito por uma nova geração de mul- 
heres que criam iniciativas para se apropriar dos games no Brasil e no mundo.

\section{PALAVRAS-CHAVE}

Videogames, Gênero, Tecnologia, Feminismo, Mulher.

\section{Abstract}

In this article, the digital gaps generated by gender hierarchies that affect the way in which women develop, disseminate and appropriate technologies are investigated. For this, some relationships between gender and technology were shown to bring the universe of games closer. Then comes a redemption of the concept of games as a "boys thing", to show how this technology gradually distanced itself from the world of girls. Today, the reverse path is being taken by a new generation of women who create initiatives for the appropriation of games in Brazil and around the world.

\section{KEYWORDS}

Video games, Gender, Technology, Feminism, Woman.

\section{Resumen}

En este documento, buscamos investigar las brechas digitales generadas por las jerarquías de género que afectan la forma en que las mujeres desarrollan, difunden y se apropian de las tecnologías. Para hacerlo, mostramos algunas relaciones entre género y tecnología para acercarnos al universo de los juegos. Luego viene una redención del concepto de juegos como "cosa de niños", para mostrar cómo esta tecnología se fue distanciando gradualmente del mundo de las niñas. Hoy, el camino inverso lo está tomando una nueva generación de mujeres que crean iniciativas para juegos apropiados en Brasil y en todo el mundo.

\section{PALABRAS CLAVE}

Videojuegos, Género, Tecnología, Feminismo, Mujer.

\section{INTRODUÇÃO}

Durante muito tempo a ciência e a tecnologia ostentaram uma suposta neutralidade, como se sua construção e manutenção não estivessem fundamentadas na hierarquização de sujeitos com base em sua classe social, gênero, etnia, raça etc. O sujeito tradicional da ciência é o sujeito hegemônico, sujeito do colonialismo, branco, europeu, heteronormativo e pertencente a classes sociais privilegiadas (Freitas et al., 2017).

Esse cenário vem se transformando aos poucos, motivado pelas agendas feministas e pelos estudos de gênero, estudos negros, estudos indígenas, entre outros. Estes estudos buscam evidenciar que, além de não se tratar de construções neutras, a ciência e, consequentemente, a tecnologia são parte de uma estrutura de relações de poder baseadas numa sociedade patriarcal e androcêntrica (Freitas et al., 2017).

Historicamente, a discussão a respeito da categoria "gênero" implica em diversas perspectivas e impasses entre pesquisadores, levando esse campo de estudo a diferentes abordagens e linhas de pensamento. Mais de que uma simples categoria baseada em elementos fisiológicos, o gênero deve ser compreendido como uma forma cultural de classificação, parte de um sistema relacional e hierarquizador que estabelece distinções baseado na violência simbólica. Para além das dicotomias do homem/ 
mulher, gênero feminino/gênero masculino, trata-se de uma categoria abstrata que tem por objetivo "explicar e desconstruir diferenciações baseadas nas percepções sociais sobre o sexo, o corpo, a cultura" (Natansohn, 2014, p. 5).

Pautamo-nos aqui na perspectiva defendida pela pesquisadora Linda Nicholson, que, em seu artigo "Interpretando o gênero", leva-nos a pensar o corpo biológico como algo complexo, que deve ser analisado dentro de uma história e uma cultura, sob a ótica de uma variável, e não uma constante. A autora alerta para os perigos de pensar gênero como dependente do corpo biológico, o que contribuiria para a exclusão daqueles que diferem da heterossexualidade normativa, pautada na oposição binária masculino/feminino (Nicholson, 2000).

Para pensar a categoria mulher se faz necessário abandonar a dicotomia masculino/feminino, compreendendo-a como uma complexa rede de características que se entrecruzam (Nicholson, 2000). A autora se baseia nas ideias de Ludwig Wittgenstein sobre linguagem para argumentar que o sentido de mulher não deve ser definido por meio de uma característica ou conjunto delas, mas, sim, a partir de uma complexa rede de características, com diferentes elementos presentes em diferentes casos.

Assim, sugiro pensarmos o sentido de "mulher" como capaz de ilustrar o mapa de semelhanças e diferenças que se cruzam. Nesse mapa o corpo não desaparece; ele se torna uma variável historicamente específica cujo sentido e importância são reconhecidos como potencialmente diferentes em contextos históricos variáveis. (Nicholson, 2000, p. 36)

A filósofa e pesquisadora Judith Butler corrobora Nicholson ao abandonar a ideia de uma definição exata para a categoria mulher, o que, segundo ela, apenas reforçaria ainda mais o binarismo masculino/feminino de matriz heterossexual (Butler, 2018). A autora, em seu livro Problemas de gênero, coloca à prova a categoria do sujeito, argumentando que esse trata-se de um construto performativo, logo, mulher "em si é um termo em processo, um devir, um construir do qual não se pode dizer legitimamente que tenha origem ou fim" (Butler, 2018, p. 69). Consideramos, portanto, "mulher" como essa complexa rede de características que se cruzam, uma constante construção, sem definição fixa. Ou seja, o sentido de mulher aqui não está restrito a uma característica específica física, social ou psicológica, ou a um conjunto delas, mas, sim, ao emaranhado de atributos que possibilitam mapear semelhanças e reconhecer diferenças desses sujeitos.

Neste trabalho, buscamos compreender os games pela ótica das tecnologias de gênero, termo cunhado pela escritora Teresa de Lauretis que diz respeito às "técnicas e estratégias discursivas" com as quais se constroem as relações de gênero específicas (De Lauretis, 1994, p. 38). Nesta perspectiva, o gênero não se trata de uma propriedade dos corpos, ou seja, algo natural aos seres humanos, mas de um conjunto de efeitos "produzidos nos corpos, comportamentos e relações sociais" (Pereira, 2009, p. 486). Para a autora, gênero é produto de diferentes tecnologias sociais, tais como televisão, cinema, jornal, internet e, consequentemente, games. Dessa forma, o gênero não é propriedade dos corpos, mas um conjunto de efeitos produzidos sobre eles.

Ao longo deste trabalho o enfoque estará nas questões de gênero, direcionado à experiência de mulheres no contexto virtual e, em especial, dos jogos digitais, mas é importante, no entanto, reforçar que gênero nesta pesquisa não se trata de um sinônimo de mulher. Os sujeitos centrais abordados ao longo desta pesquisa 
identificam-se como mulheres, mas nesse recorte há multiplicidade de identidades criadas discursivamente que articulam, além do gênero, raça, origem geográfica, classe social, contexto cultural, orientação sexual, entre outros, que evidenciam a necessidade de uma abordagem sob lentes "interseccionais", termo que diz respeito à interdependência das relações de poder de raça, sexo e classe.

O conceito de interseccionalidade, cunhado academicamente pela afro-estadunidense Kimberlé Crenshaw em 1989, permite enxergar as sobreposições de gênero, raça e classe e define o posicionamento do feminismo negro frente à ideia de um feminismo global e hegemonicamente branco. Apesar do termo se tornar popular no contexto acadêmico a partir dos anos 2000, sua origem está atrelada ao movimento feminista negro dos anos 1970, conhecido como Black Feminism, que buscava criticar a hegemonia do feminismo branco, europeu, heterossexual e de classe média. "A interseccionalidade é vista como uma das formas de combater as opressões múltiplas e imbricadas, e portanto como um instrumento de luta política" (Hirata, 2014, p. 69).

\subsection{A BRECHA TECNOLÓGICA DE GÊNERO}

Historicamente o trabalho produtivo foi designado ao gênero masculino, reservando para as mulheres as funções de atendimento às necessidades básicas e de bem-estar social, ligadas essencialmente a questões de cuidado e de reprodução. Se antigamente elas eram exclusivamente ligadas a funções como cuidar da casa, educar os filhos e se dedicar a atividades de artesanato, ainda hoje esses estereótipos se reproduzem com a imagem feminina fortemente relacionada a funções de cuidado, estando em sua maioria ligadas a áreas como enfermagem, recursos humanos, comunicação, educação etc.
A exclusão feminina do fazer científico e tecnológico foi pautada por discursos científicos, que postulavam, a partir de determinações biológicas, que a mulher seria menos capaz de produzir ciência e tecnologia. Estudos mais recentes apontam inquietudes sobre esse universo hegemônico, androcêntrico e sexista na ciência e na tecnologia. (Freitas et al., 2017, p. 4)

Em linhas gerais, os estudos de gênero em ciência e tecnologia apontam que esses saberes foram instituídos a partir de bases epistemológicas e filosóficas masculinas. A ciência foi construída por homens e para homens. Não por um determinismo biológico que justifique o afastamento de mulheres dessas áreas, mas por uma construção arquitetada para manter privilégios masculinos sobre o contexto hegemônico androcêntrico da ciência.

O conceito de suposto determinismo biológico foi fortemente utilizado para perpetuar a ideia de que mulheres possuem capacidades inferiores aos homens em determinadas áreas, entre elas a ciência, a tecnologia e os games. Um conceito equivocado que desconsidera completamente o contexto social no qual o sujeito está inserido (Nicholson, 2000). O afastamento das mulheres da tecnologia não se baseia em fatores biológicos, e sim em uma brecha tecnológica de gênero.

Essa brecha diz respeito não somente aos obstáculos enfrentados pelas mulheres para o acesso às Tecnologias da Informação e Comunicação (TICS), mas envolve também dimensões sociais de como o gênero opera de forma hierarquizadora no desenho, distribuição e apropriação das tecnologias pelo gênero feminino (Natansohn, 2013).

Se observada a história dos grandes avanços tecnológicos, por exemplo, é possível identifi- 
car dois fatores: primeiro, que a tecnologia é projetada, moldada e difundida por homens brancos na academia e no complexo industrial militar; segundo, quando mulheres de alguma forma conseguem atravessar essa brecha que segrega a participação por gênero na tecnologia, ocorre um apagamento histórico e sistemático da atuação feminina, como, por exemplo, o fato de Ada Lovelace ${ }^{1}$ e Hedy Lamarr ${ }^{2}$ serem importantes nomes da tecnologia e passarem desapercebidos para a maioria das pessoas.

What we learn from the history of the internet is that it was engineered, implemented, programmed, and spread by white men in academia and the military-industrial complex. Despite the fact that the earliest computer programmers were actually women, the creators of ARPANET and the earliest desk-sized computers were educated white men with ties to research institutions and the government, spaces which have historically been associated with white male authority and privilege. ${ }^{3}$ (Bezio, 2018)

No livro Internet em código feminino: teorias e práticas, a autora Graciela Natansohn utiliza o exemplo da experiência infantil de meninos e meninas ao desmontarem seus brinquedos para ilustrar o que ela chama de "hábitus tecnológico binário, hierárquico e altamente des-

1 Ada Lovelace (1815-1852), matemática e escritora inglesa, criou o primeiro algoritmo para ser processado por uma máquina. É considerada a primeira programadora de toda a história.

2 Hedy Lamarr (1914-2000), atriz e inventora, criou um sistema de comunicações para as Forças Armadas dos EUA que serviu como base para a invenção do Wi-Fi e da atual telefonia celular.

3 Em tradução livre: "O que aprendemos com a história da internet é que ela foi projetada, implementada, programada e difundida por homens brancos na academia e no complexo industrial/militar. Apesar de os primeiros programadores de computador serem mulheres, os criadores da ARPANET e dos primeiros computadores de mesa foram homens brancos instruídos com vínculos com instituições de pesquisa e com o governo, espaços historicamente associados à autoridade e privilégio de homens brancos". favorável às meninas" (Natansohn, 2013, p. 17). Segundo a autora, os meninos são estimulados a desmontar e (tentar) remontar seus brinquedos num exercício da curiosidade criativa fundamental ao fazer tecnológico, enquanto as meninas, na mesma situação de desconstruir suas bonecas, são repreendidas e desestimuladas, encorajadas a demonstrar zelo e responsabilidade com seus pertences, empurradas ao ofício do cuidado, de bem-estar social e de reprodução.

Justine Cassell e Henry Jenkins apresentam dados no livro From Barbie to Mortal Kombat: gender in computer games, de 1998, que corroboram com a visão de Natansohn. Os autores investigam o contexto norte-americano da cultura gamer na década de 1990 e debatem as relações de gênero nos jogos de computador a partir de referências culturais, valores e atribuições aos jogos de acordo com o gênero das crianças.

Para eles, o imaginário de que o gênero feminino não tem interesse em jogos digitais não se dá pelo suposto determinismo biológico, mas, sim, pelo fato de que os homens dominam o acesso aos computadores, excluindo as mulheres da cena. Os autores citam um estudo realizado com crianças em idade pré-escolar em que os meninos se apropriavam dos computadores, limitando o acesso das meninas. 0 menor tempo de exposição das meninas aos computadores e aos jogos se refletia na falta de interesse delas por estes. No entanto, após a mediação de professores, garantindo o acesso com equidade entre meninos e meninas, ambos apresentavam interesse semelhante pelos jogos (Cassell e Jenkins, 1998).

Diversos fatores implicam diretamente nessa "fratura tecnológica de gênero", como: letramento, afinal, para utilizar os recursos tecnológicos é necessário ler e escrever; capacitação 
em informática; domínio básico da língua inglesa, uma vez que esta é predominante em softwares, sites e dispositivos tecnológicos; recursos econômicos para adquirir e pagar o acesso; produção e divulgação de conteúdos úteis às mulheres; e, por fim, oportunidades de inserção do gênero feminino em contextos de desenvolvimento da ciência e tecnologia (Alonso, 2007 apud Natansohn, 2013).

Natansohn (2013) lista três tipos de brechas digitais de gênero: (a) a capacidade de acesso às redes; (b) o uso que as pessoas fazem da tecnologia; e (c) o lugar das mulheres na produção e governança tecnológica.

Trazendo essa perspectiva para os games, a brecha tecnológica é bastante sintomática, de forma que é possível observar os três tipos de brecha digital:

a) A capacidade de acesso às redes: dados demonstram que o gênero feminino se apropria mais facilmente de jogos mobile, ou seja, para dispositivos móveis como smartphones e tablets, enquanto o masculino domina o espectro dos consoles e computadores (SIOUX GROUP et al., 2019). Os números apontam também que a utilização de internet por meio de dispositivos móveis no Brasil é igualitária entre os gêneros, sendo que $74 \%$ dos indivíduos de sexo ${ }^{4}$ masculino e $75 \%$ de sexo feminino afirmam ter utilizado a internet no telefone celular nos últimos três meses. Já em relação ao computador, 63\% dos indivíduos de sexo masculino já utilizaram computador, enquanto apenas 58\% dos indivíduos de sexo feminino o fizeram.

Uma das explicações para esse fenômeno é de que a popularização dos smartphones e

4 A pesquisa TIC Domicílios 2018 não possui recorte por gênero, apenas por sexo. dos planos pré-pagos de internet possibilitam um maior acesso do gênero feminino a esses dispositivos. A maior parte dos jogos mobile pode ser jogada off-line, não depende necessariamente de internet móvel ou sinal de Wi-Fi para rodar, o que demanda menos recurso financeiro e possibilita o acesso das mulheres a esses jogos.

b) 0 uso que as pessoas fazem da tecnologia: os jogos mobilem são considerados jogos "casuais", dificilmente são levados a competições de nível profissional, possuem pouca ou nenhuma publicidade e não acarretam a seus jogadores o status de "gamers". Esses jogos são marginalizados na cultura mainstream dos videogames, considerados menos relevantes ou, ainda, como jogos de "mulheres".

\section{c) O lugar das mulheres na produção e} governança tecnológica: segundo dados do Censo realizado em 2018, as mulheres representam apenas 20,7\% da força de trabalho entre sócios e funcionários das empresas de produção de games (Sakuda e Fortim, 2018). Se observado o recorte por área de atuação dentro da indústria, essa brecha se mostra ainda maior, o gênero feminino se concentra em atividades de marketing, vendas e administração, representando apenas 10,8\% nas áreas diretamente relacionadas ao fazer tecnológico, como programação e gestão de projetos.

O exemplo anterior ilustra a forma como a brecha digital de gênero marginaliza a participação das mulheres na experiência dos jogos digitais. Mais do que plataformas de entretenimento, os games podem ser considerados a primeira e provavelmente a mais atraente forma de introdução de crianças ao universo tecnológico.

A experiência com os jogos digitais abre uma porta para o interesse e a apropriação do cam- 
po da tecnologia desde a infância, com implicações diretas na maneira como as relações de poder baseadas na hierarquização de gênero se perpetuam no campo da ciência e da tecnologia. A forma como essa brecha digital se consolidou desde os primórdios da indústria gamer é o que veremos a seguir.

\subsection{AFINAL, GAME É COISA DE MENINO?}

A percepção de que os games são "coisa de menino" está profundamente enraizada na sociedade, baseada na crença de um suposto determinismo biológico pelo qual o gênero masculino teria mais interesse e aptidão para os jogos digitais. No entanto, se observada a breve história dos videogames, fica evidente que essa hegemonia masculina se dá devido ao fato de que a estrutura científica e tecnológica, base da indústria gamer, é pautada em relações de poder patriarcais e androcêntricas.

Os primeiros videogames surgiram em 1952, a partir da versão computadorizada do Tic Tac Toe, ou Jogo da Velha, programada por Alexander Douglas na Universidade de Cambridge. Em 1958, William Higinbotham produziu uma versão do osciloscópio de Ping Pong no Brookhaven National Laboratory do Departamento de Energia dos EUA e finalmente, em 1962, nasce o Spacewar!, o primeiro jogo de computador que não se tratava de uma versão digitalizada de outro jogo, desenvolvido por uma equipe de pesquisadores do MIT liderada por Steve Russell (Bezio, 2018).

O que a criação desses jogos tem em comum é que, assim como a internet, seus desenvolvedores (e, consequentemente, os jogadores) eram homens brancos altamente instruídos que trabalhavam na academia ou no complexo industrial e militar na Inglaterra ou nos Estados Unidos. Com isso, os jogos criados nas décadas de 1970 e 1980, e que acabam por se perpetuar até os dias de hoje, não exclusivamente, mas em grande número, são narrativas centradas em figuras masculinas de soldados, aventureiros, ciborgues e criminosos.

A despeito desse cenário, a década de 1970 marca o início de um período de ascensão feminina à mídia e ao mercado de trabalho. Não por acaso, durante esse período os primeiros consoles de videogames começaram a ser vendidos como entretenimento para toda a família, sem distinção de idade e gênero entre o público, de forma semelhante à estratégia utilizada para comercialização de eletrodomésticos como a televisão ou o rádio, por exemplo.

A Figura 1 ilustra a estratégia utilizada pela empresa Atari para divulgação do console Atari 2600, lançado nos EUA em 1977, que chegou ao Brasil em 1983. Observa-se que o console é intitulado de "inimigo da família brasileira", em alusão a uma atividade realizada em família na qual pai, mãe e crianças combatiam de forma conjunta e sem distinções os diversos vilões presentes nos jogos (Figura 1).

Durante a década 1980 a indústria de videogames enfrentou uma grande baixa de vendas motivada pela crise financeira nos EUA e a forte concorrência das recém-chegadas empresas japonesas ao mercado americano. Nesse momento, a japonesa Nintendo optou por reposicionar os videogames como brinquedos masculinos, por entender que este se tratava de um setor mais bem estabelecido e de demanda estável se comparado ao mercado de eletrodomésticos, que em momentos de crise passavam a ser vistos pelos consumidores como bens supérfluos. 


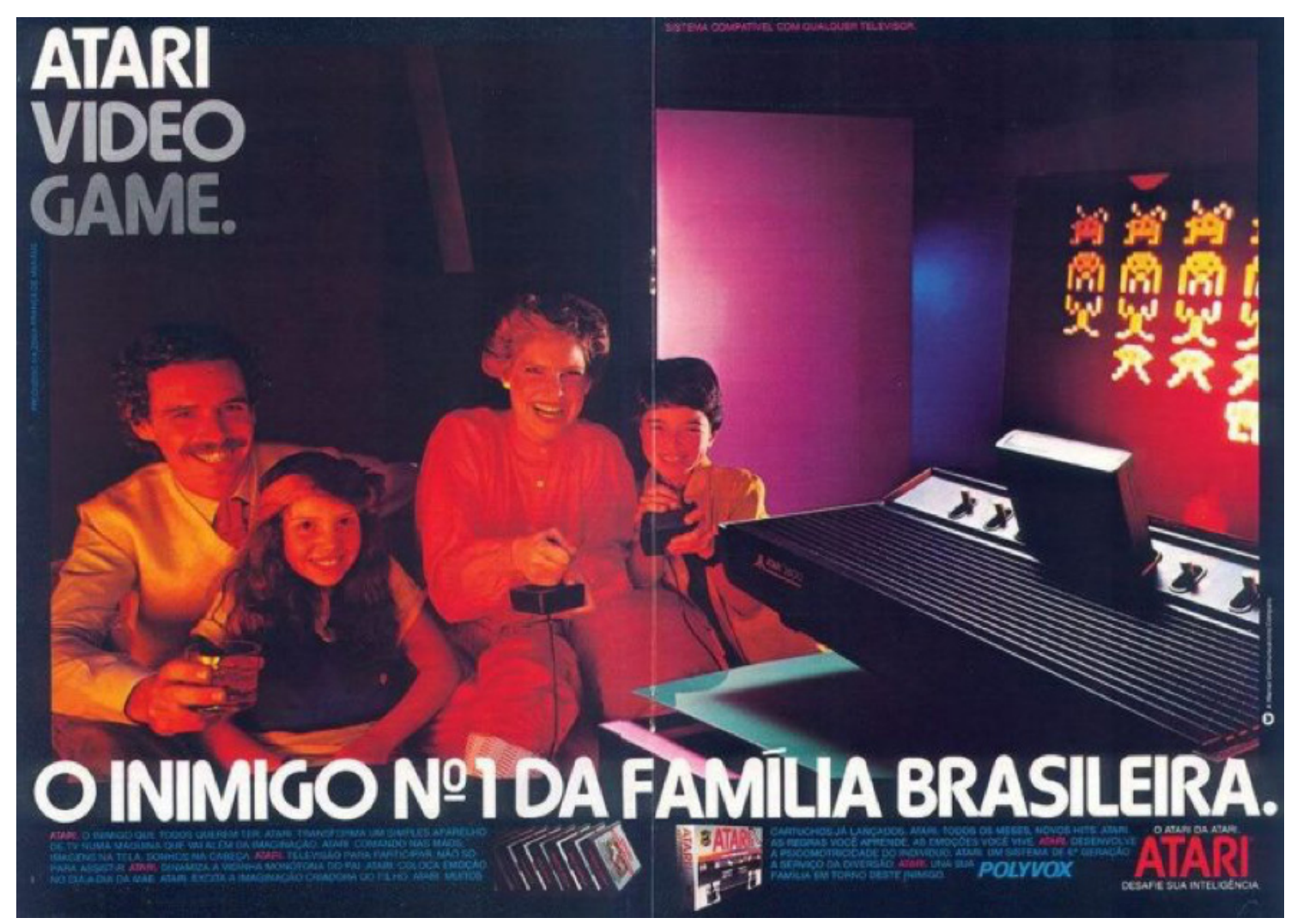

Figura 1. Propaganda do console Atari 2600. Fonte: REIS JR, 2019.

A Figura 2 apresenta uma sequência de imagens extraídas da primeira propaganda ${ }^{5}$ feita para televisão do console Nintendo NES, lançado em 1983 no Japão, que chegou aos EUA em 1985. No vídeo, dois jovens brancos de gênero masculino jogam de maneira entusiasmada na companhia do robô Rob, item que acompanha o jogo.

Tal estratégia se mostrou eficaz durante um tempo, sendo seguida pelas demais empresas do ramo e, desde então, os videogames passaram a ser direcionados para o público jovem e masculino (Blanco, 2017). Dados de 1998 apontam que nesse período, o público gamer era formado em $80 \%$ pelo gênero masculino (Bezio, 2018).

5. O vídeo completo da propaganda pode ser assistido em: https://www.youtube.com/watch?v=IU1-ncmPijk. Acesso em: 23 mar. 2019.

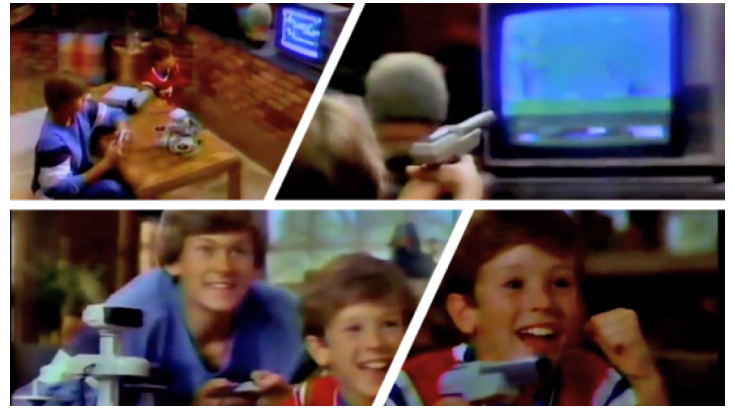

Figura 2. Comercial televisivo de lançamento do Nintendo NES em 1985, nos EUA. Fonte: adaptada de Retro Games Fan, [s.d.].

Outro elemento que pode ter grande influência na baixa aderência feminina aos games está relacionado aos fliperamas, máquinas de jogos disponibilizadas em espaços públicos ou em casas especializadas. Nesses locais, muito populares nos Estados Unidos da América (EUA) durante os anos 1980, os arcades, como eram conhecidos, eram acionados por moedas ou 
fichas e foram responsáveis por popularizar os videogames entre o público que ainda não tinha acesso aos consoles domésticos. Esses locais, no entanto, tinham reputação duvidosa, sendo constantemente comparados às casas de caça-níquel controladas em grande parte pela máfia, o que afastava o público feminino (Donovan, 2010 apud Blanco, 2017).

A estrutura social baseada em preceitos misóginos impedia que as meninas frequentassem esses locais, empurrando-as para ocupações como brincar de bonecas ou realizar as atividades domésticas enquanto os meninos se divertiam e se habituavam aos desafios dos games, que, de acordo com diversas pesquisas, têm potencial para contribuir para o desenvolvimento do raciocínio lógico (McGonigal, 2017). "Gaming might help develop confidence and skills in using digital technologies, leading to an increased interest and aptitude for careers in computer science and other fields that heavily rely on such technologies ${ }^{6 \prime}$ (Hayes, 2007, p. 23).

Tōru Iwatani, criador do Pac-Man, parece ter percebido esse afastamento das meninas dos fliperamas e afirma ter desenvolvido esse game com o objetivo de atrair o público feminino para esses espaços. Para criar o personagem, Iwatani teria associado a imagem de mulheres à comida e, inspirado por um pedaço de pizza, acabou criando um dos personagens mais icônicos dos videogames (Blanco, 2017).

Apesar do grande sucesso de Pac-Man, apenas no início dos anos 1990 a indústria identificou a oportunidade de investir no público feminino, motivada por fatores como a saturação do mercado, a introdução do CD-ROM e as discussões acerca do gap de gênero na área de

6 Em tradução livre: Os jogos podem ajudar a desenvolver confiança e habilidades no uso de tecnologia digital, levando a um maior interesse e aptidão para carreiras em ciência da computação e outros campos que dependem fortemente dessas tecnologias. tecnologia (Cassell e Jenkins, 2011). Esses fatores culminaram no lançamento do jogo Barbie Fashion Designer, produzido pela Mattel em 1996, que explorava a marca da boneca Barbie, bastante consolidada entre o público feminino, e tinha como diferencial se tratar de uma mídia de computador, sendo comercializada sem a necessidade de aquisição de um console específico. Esse ponto é bastante relevante, haja vista o direcionamento que a indústria de videogames havia dado aos consoles de "produto masculino" durante a década anterior.

O jogo da Barbie dá início a um movimento chamado Pink Games (Jogos Cor-de-Rosa), baseado no estereótipo de que as meninas se interessavam apenas em temáticas de roupas, maquiagem, beleza e atividades consideradas "do lar" (Cassell e Jenkins, 2011). (Figura 3).

Os chamados Pink Games acabaram por reforçar a figura da mulher em posições objetificadas e sexistas. Em oposição a essa perspectiva, o Girl Games Movement buscou proporcionar práticas conjuntas entre desenvolvedores, pesquisadores da área de estudos de gênero e militantes dos movimentos feministas na produção de jogos que dessem me-

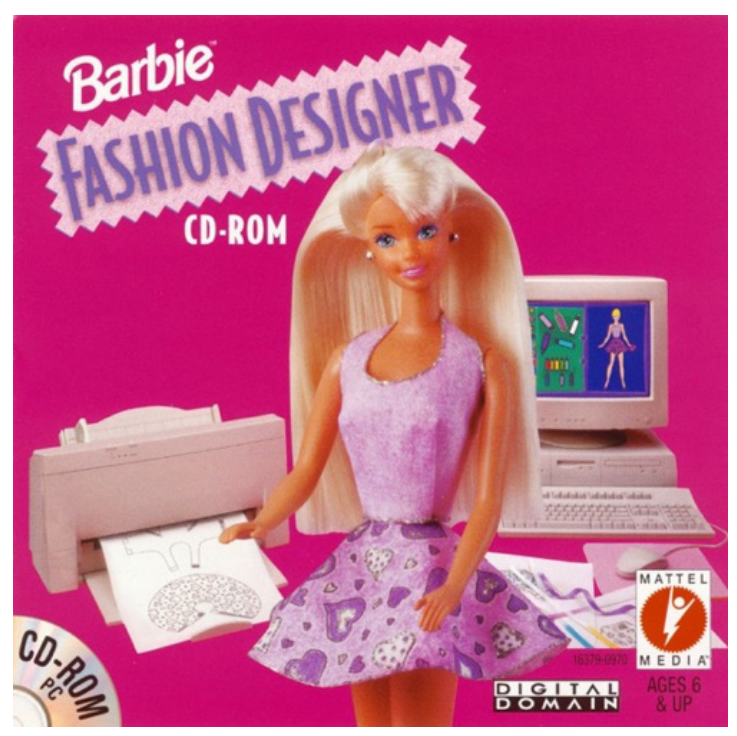

Figura 3. Capa do CD-ROM do jogo Barbie Fashion Designer, Mattel, 1996. Fonte: Barbie, [s.d.]. 
nos ênfase aos aspectos da "feminilidade" dos Pink Games e buscassem construir narrativas que valorizassem a experiência das mulheres nos jogos digitais.

Em 1995, Theresa Duncan e Mônica Gesue lançam o jogo Chop Suey, uma história interativa de duas garotas aventureiras e fãs de comida chinesa. Esse jogo inaugura uma tendência alternativa aos Pink Games, com jogos também voltados ao público feminino, no entanto, com enfoque em questões de socialização, resolução de conflitos e reprodução de situações vivenciadas por meninas de 8 a 12 anos. Esses jogos, que viriam a ficar conhecidos como Purple Games, em sua grande maioria foram desenvolvidos pela produtora Purple Moon (Blanco, 2017). (Figura 4).

Apesar de fugirem ao estereótipo de uma feminilidade baseada em roupas, maquiagens e afazeres domésticos, os Purple Games estavam baseados na ideia de que as mulheres seriam naturalmente mais sociáveis e conciliadoras do que os homens. Ambos os casos se apoiam numa suposta feminilidade pautada na oposição binária masculino/feminino.

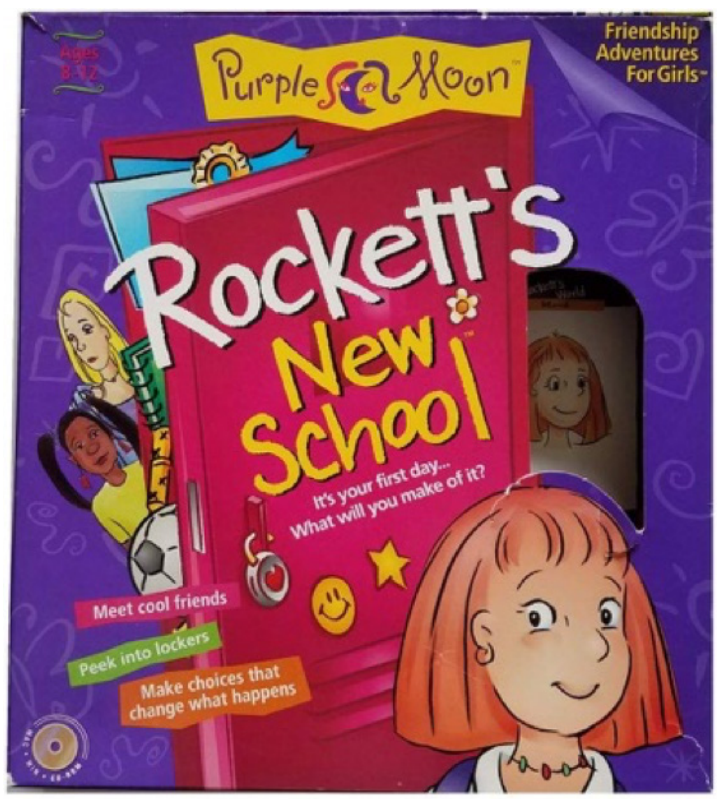

Figura 4. Capa do jogo Rockett's New School (1997) da Purple Moon. Fonte: Rockett's New School, [s.d.].
O pensamento por trás dos jogos considerados como Purple Games parte de uma perspectiva feminista denominada "diferencialista", ou ainda, "essencialista", marcada pelas lutas por afirmação das diferenças e da identidade, que considerava o sexo genital como diferenciador em relação aos homens e, portanto, formador de uma identidade feminina. Essa perspectiva foi intensamente criticada por autoras como Butler (2018), Nicholson (2000) e Scott (1989), que, entre suas especificidades, abordam o gênero como uma construção social e cultural, efeito das representações discursivas.

O estudo de caso registrado no artigo "Gendered identities at play: case studies of two women playing Morrowind", de Elisabeth Hayes (2007), corrobora as autoras supracitadas ao criticar o que ela define como concepções limitadas da natureza do gênero e sua manifestação nos comportamentos e autopercepção das pessoas em relação à forma como o mercado e parte da academia identifica as supostas preferências femininas em relação aos games. Para a autora, o estereótipo de que gamers de gênero feminino preferem jogos casuais, colaborativos e com foco em interações sociais enquanto gamers do gênero masculino optam por jogos competitivos e de combate não reflete as múltiplas camadas pelas quais os indivíduos constroem sua identidade, como questões de classe, raça, história pessoal e fatores culturais que diferem na vida de cada um (Hayes, 2007).

Um exemplo são as Grrrl Gamers, mulheres que na década de 1990 fugiam do padrão estereotipado dos Pink Games e optavam por jogos considerados "masculinos", forçando o reconhecimento de sua presença e habilidade naquele espaço. Essas mulheres não buscavam um segmento próprio dentro dos jogos, mas, sim, reivindicavam sua representatividade em todos os tipos de games, tornando as arenas virtuais verdadeiros territórios de resistência. 
O Girls Games Movement foi perdendo força no final da década de 1990, mas sua semente foi plantada no solo fértil dos games que passavam por um verdadeiro processo de ascensão, impulsionado pelo avanço da tecnologia no desenvolvimento de consoles e computadores pessoais (PCs), aliado à popularização da internet de banda larga. Nesse contexto, a comunidade feminina continuou a ocupar espaços chegando, em 2018, a representar 46\% do público global de games (Newzoo, 2019). No Brasil, nos últimos três anos, as mulheres são maioria entre os praticantes de jogos digitais, e em 2018 elas representam a maioria entre o público (Sioux Group et al., 2019).

Em função desse cenário de rápida inserção feminina no universo gamer, movimentos que buscam dar maior visibilidade às mulheres da cena gamer, assim como protegê-las dos constantes ataques contra sua presença nos jogos, vêm crescendo e se solidificando, o que auxilia na busca pela maior equidade entre gêneros nesse ambiente.

\section{CONCLUSÕES}

Diferentemente de uma certa "naturalização" que pode ser considerada ao se tratar das diferenças de gênero no acesso e na prática de games, buscamos mostrar nesse trabalho que o desequilíbrio existente hoje no mercado de games é reflexo tanto de contexto histórico de distanciamento induzido do acesso das mulheres à tecnologia, como da decisão da indústria de games por direcionar, a partir de um certo momento, seus esforços para o público masculino.

No entanto, observada a literatura, fica evidente o interesse da academia, em especial na última década, em investigar como se dá a representatividade feminina nos games bem como a experiência das mulheres no contexto dos jogos eletrônicos, dado o avanço da participação feminina na comunidade gamer e a demanda por oportunidades igualitárias no cenário profissional competitivo dos games.

A luta das mulheres gamers por espaço e reconhecimento encontra resistência por parte da comunidade que interpreta a ascensão feminina como uma invasão a um espaço até então reservado à expressão de uma masculinidade ancorada na violência e virilidade. Essa resistência, no entanto, tem sido combatida por meio de coletivos e projetos de mulheres que buscam garantir a apropriação feminina da cena gamer.

O que tentamos mostrar aqui foi a origem desses campos de tensão construída a partir das relações entre gênero e tecnologia, na qual o gênero opera como um elemento hierarquizador com notável prejuízo ao acesso das mulheres a esse campo de domínio do conhecimento. 


\section{BIBLIOGRAFÍA}

Bezio, K. Ms. (2018). Ctrl-Alt-Del: GamerGate as a precursor to the rise of the alt-right. Leadership, 14(5), 556-566. doi:10.1177/1742715018793744

Blanco, B. (2017). Games para mulheres: do Girls Game Movement ao pós Gamergate. En Anais do Congresso Intercom - Sociedade Brasileira De Estudos Interdisciplinares Da Comunicação. Curitiba: Intercom. Recuperado de: http://portalintercom.org.br/anais/nacional2017/resumos/R120280-1.pdf

Butler, J. P. (2018). Problemas de gênero: feminismo e subversão da identidade (16. ed.). Rio de Janeiro: Civilização Brasileira.

Cassell, J. e Jenkins, H. (2011). From Quake Grrls to Desperate Housewives: A Decade of Gender and Computer Games. In: Kafai, Y. B., Jenkins, H. (Eds.). Beyond Barbie to Mortal Kombat - New Perspectives on Gender and Gaming. Cambridge, Massachusetts London: MIT Press.

Cassell, J. e Jenkins, H. (1998). From Barbie to Mortal Kombat: gender and computer games. 1. ed. Cambridge, Mass.: MIT Press. Recuperado de: https://archive.org/details/frombarbietomort00cass\#maincontent

De Lauretis, T. (1994). A tecnologia do gênero. In: Tendências e impasses: o feminismo como crítica da cultura. Rio de Janeiro: Rocco, 206-242.

Freitas, L. B. et al. (2017). Gênero, Ciência e Tecnologia: estado da arte a partir de periódicos de gênero. Cadernos Pagu, 49. doi:10.1590/1809444 9201700490008.

Hayes, E. (2007). Gendered Identities at Play: Case Studies of Two Women Playing Morrowind. Games and Culture, 2(1), 23-48. doi:10.1177/1555412006294768

Hirata, H. (2014). Gênero, classe e raça Interseccionalidade e consubstancialidade das relações sociais. Tempo Social, 26(1), 61-73. doi:10.1590/ S0103-20702014000100005

McGonigal, J. (2017). A realidade em jogo. Rio de Janeiro: Editora Best Seller.

Natansohn, G. (2014). Mulheres e uso das TIC, algumas reflexões metodológicas. En Anais do Intercom - Sociedade Brasileira De Estudos Interdisciplinares Da Comunicação. Foz do Iguaçu: Intercom. Recuperado de: http:// gigaufba.net/wp-content/uploads/2014/09/Mulheres-USO-TIC-Intercom2014Natansohn2014.pdf

Natansohn, G. (Ed.) (2013). Internet em código feminino. Teorias e práticas. (1. ed.). Buenos Aires: La Crujía. Recuperado de: http://gigaufba.net/internet-em-codigo-feminino/

Newzoo. (2019). Newzoo's Gamer Segmentation. Recuperado de: https://resources.newzoo.com/hubfs/Newzoo_Gamer_Segmentation.pdf

Nicholson, L. (2000). Interpretando o gênero. Revista Estudos Feministas, 8(2), 9-42. doi:10.1590/\%25x 
Pereira, P. P. G. (2009). Violence and technologies of gender: time and space in the newspaper. Revista Estudos Feministas, 17(2), 485-505.

Sakuda, L. O. e Fortim, I. (Eds.) (2018). // Censo da Industria Brasileira de Jogos Digitais. Brasília: Ministério da Cultura. Recuperado de: https://nuvem. cultura.gov.br/index.php/s/mdxtGP2QSYO7VMz\#pdfviewer

Scott, J. (1989). Gênero: uma categoria útil de análise histórica. Gender and the politics of history, 20(2), 35, 1989.

Sioux Group et al. (2019). Pesquisa Game Brasil 2019. São Paulo: Sioux Group. Recuperado de: https://www.pesquisagamebrasil.com.br/

\section{FONTES DAS IMAGENS}

1. Reis Jr., D. (2019). Atari Polyvox - 1978 Propagandas Históricas | Propagandas Antigas. Recuperado de: https://www.propagandashistoricas. com.br/2013/02/atari-polyvox-1978.html

2. $\quad$ Original Nintendo NES Commercial First TV Ad 1985. [s.d.]. Direção: RETRO GAMES FAN. Recuperado de: https://www.youtube.com/watch?$v=\mid U 1-n c m P i J k$

3. Barbie Fashion Designer (1996) Windows box cover art. [s.d.]. Recuperado de: https://www.mobygames.com/game/windows/barbie-fashion-designer/cover-art/gameCoverld,87484/

4. Rockett's New School. [s.d.]. Recuperado de: https://purplemoon.fandom.com/wiki/Rockett\%27s_New_School 